\title{
EXPERIMENTAL STUDY OF RHEOLOGICAL PROPERTIES OF Fe-C-O-Cr ALLOYS
}

\author{
Lenka ŘEHÁČKOVÁ, Vlastimil NOVÁK, Bedřich SMETANA, L'ubomíra DROZDOVÁ, \\ Jana DOBROVSKÁ, Filip RADKOVSKÝ
}

VSB - Technical University of Ostrava, Ostrava, Czech Republic, EU, lenka.rehackova@vsb.cz

https://doi.org/10.37904/metal.2019.792

\begin{abstract}
Rheological properties (dynamic viscosity, flow curves) of selected $\mathrm{Fe}-\mathrm{C}-\mathrm{O}-\mathrm{Cr}$ alloys were experimentally investigated with the use of a high-temperature rotating viscometer Anton Paar FRS 1600. The viscosity of concerned alloys was measured during cooling at a rate of $2.5^{\circ} \mathrm{C} / \mathrm{min}$. The maximum temperature achieved within experiments was $1,550^{\circ} \mathrm{C}$. The flow curves were recorded at this temperature to assess flow properties. According to their shape, all alloys exhibited non-Newtonian behaviour. At the temperature of $1,550{ }^{\circ} \mathrm{C}$, the alloys behaved as shear thickening fluids. Given that viscosity depends mainly on the change in temperature and chemical composition, these aspects were considered in this work. Two series of model Fe-C-O-Cr alloys, which differed in chromium (0.924 wt. $\%$ - 4.795 wt. $\%)$ and carbon (0.042 wt.\% - 1.378 wt.\%) content, were selected to examine the influence of these elements. In the given concentration ranges, only slight dependence of viscosity on chromium and carbon content was found. Further, the viscosity increased exponentially with decreasing temperature at measured temperature intervals of $1,550{ }^{\circ} \mathrm{C}-1,450{ }^{\circ} \mathrm{C}\left(1,350{ }^{\circ} \mathrm{C}\right)$.
\end{abstract}

Keywords: Dynamic viscosity, flow curves, non-Newtonian fluid, Fe-alloy

\section{INTRODUCTION}

Knowledge of the thermo-physical properties of molten metals such as density, viscosity, surface tension, diffusivity and thermal conductivity is highly appreciated in many industrial sectors and is the key prerequisite to the advancement of engineering procedures research. The viscosity of liquid metal systems is an essential rheological parameter and is one of the crucial transport properties affecting solidification processes, such as welding and casting. Besides that, the rate of reactions between metal and slag can be determined by continuous measurement of the viscosity of both components [1].

A correct understanding of the relationship between viscosity, shear rate and time allows estimating a solid fraction and even solid crystal size at temperatures below melting points [2]. Assessing the viscosity of partially solidified metals and alloys is an important task for structural analysis and casting processes.

Experimental determination of viscosity and other key rheological parameters of liquid metals is very challenging, especially in the light of their high melting points, chemical reactivity, oxidation characteristics, and low viscosity values. Many experimental methods have been developed or modified to measure the viscosity of liquid metals, for example, capillary technique, oscillating vessel technique, vibration spindle technique or rotational viscometry [1]. However, there are significant differences between the viscosity data obtained by different techniques. Description of the flow behaviour of liquid metals and metallic alloys is not always straight-forward. In the past, many studies have pointed to the Newtonian behaviour of liquid metals $[3,4]$. Recent efforts [5] have suggested that the liquid metal systems show tendencies of non-Newtonian flow behaviour. Varsani et al. [6] revealed that liquid metals exhibit shear-thickening behaviour, contrary to the other authors, who concerned with flow behaviour of liquid metals at a low shear rate where a shear thinning behaviour is typical for these materials [7].

Viscosity is a quantity sensitive to changes in temperature, chemical composition, and structure of a molten system. In this paper, temperature dependencies of the viscosity of $\mathrm{Fe}-\mathrm{C}-\mathrm{O}-\mathrm{Cr}$ alloys varying in chromium (0.924 wt.\% - 4.760 wt. \%) and carbon (0.042 wt.\% - 1.378 wt.\%) content were experimentally determined. 
Flow behaviour of particular systems was described by flow curves that were obtained at $1,550{ }^{\circ} \mathrm{C}$ (in a liquid state) and $1,450^{\circ} \mathrm{C}$ (in a semi-solid state).

\section{EXPERIMENTAL RESEARCH}

\subsection{Samples characterization}

Six alloys (samples 1 - 6) were selected for measurement of rheological characteristics, especially dynamic viscosity by means of high-temperature viscometer Anton Paar FRS 1600. These samples were prepared at our working site from pure metals ( $\mathrm{Fe}$ and $\mathrm{Cr}$, purity $99.99 \%$ ), carbon (purity $99.99 \%$ ) and $\mathrm{Fe}_{2} \mathrm{O}_{3}$ tablets (purity $99.999 \%$ ) by vacuum induction melting using furnace Leybold Heraus. The melt was cast into the vertically oriented mould to obtain $3 \mathrm{~kg}$ ingots from which rods of a diameter $27 \mathrm{~mm}$ were made. Their chemical composition determined by GDA $750 \mathrm{HP}$ optical emission spectrometer (GDOES) is listed in Table 1. Carbon, oxygen and sulphur contents were obtained by combustion analysers Eltra $2000 \mathrm{CS}$ and Eltra $2000 \mathrm{ONH}$. Prior to the experiment, alloy samples of cylindrical shape $(27 \mathrm{~mm}$ diameter $\times 38 \mathrm{~mm}$ height) were thoroughly mechanically cleaned to remove surface oxides.

Table 1 Chemical composition of the Fe-alloys (wt.\%)

\begin{tabular}{|c|c|c|c|c|c|c|c|}
\hline Sample & $\mathbf{C r}$ & $\mathbf{C}$ & $\mathbf{O}$ & $\mathbf{S}$ & $\mathbf{M n}$ & $\mathbf{W}$ & Co \\
\hline $\mathbf{1}$ & 0.924 & 0.344 & 0.002 & 0.068 & 0.056 & - & 0.013 \\
\hline $\mathbf{2}$ & 2.970 & 0.342 & 0.020 & 0.052 & 0.050 & 0.024 & 0.020 \\
\hline $\mathbf{3}$ & 4.796 & 0.330 & 0.002 & 0.007 & 0.041 & 0.045 & 0.011 \\
\hline $\mathbf{4}$ & 4.883 & 0.042 & 0.026 & 0.052 & 0.051 & - & 0.017 \\
\hline $\mathbf{5}$ & 4.671 & 0.650 & 0.019 & 0.053 & 0.047 & 0.036 & 0.021 \\
\hline $\mathbf{6}$ & 4.591 & 1.378 & 0.011 & 0.054 & 0.047 & 0.038 & 0.021 \\
\hline
\end{tabular}

The content of other elements $(\mathrm{Ni}, \mathrm{Si}, \mathrm{Ti}, \mathrm{Mo}, \mathrm{P}, \mathrm{Al}, \mathrm{Cu}$ and $\mathrm{Zr}$ ) present in alloys was less than $0.005 \mathrm{wt} . \%$, and the rest constituted iron.

\subsection{Measurement of rheological properties}

The dynamic viscosity measurements were carried out in a high-temperature viscometer Anton Paar FRS 1600. This viscometer is a combination of laboratory furnace and measuring head DSR 301 equipped with air bearing motor. In order to protect mechanical and electronic components from overheating, the rheometer is air and water cooled. The measuring system consists of an alumina spindle mounted on a long ceramic shaft connected to the rheometer head, and of an alumina crucible, which is fixed to the lower ceramic shaft. The equipment enables work in rotation and vibration modes. For the presented experiments, the rotation mode, which is based on measurements of torque necessary to rotate a spindle immersed in a liquid sample at a constant angular velocity, was chosen. Further, the viscometer is equipped by a high-temperature furnace which allows measurement up to temperatures of $1,550{ }^{\circ} \mathrm{C}$ registered by a Pt-13\%Rh/Pt thermocouple.

The alumina crucible, along with the alloy sample, was placed into the furnace. To avoid the oxidation of given samples, the argon (purity $>99.9999)$ - hydrogen $(2.6 \%)$ gas mixture was used at a flow rate of $150 \mathrm{l} / \mathrm{h}$. The furnace was heated to $1,550{ }^{\circ} \mathrm{C}$ at a heating rate of $17{ }^{\circ} \mathrm{C} / \mathrm{min}$ then the temperature was held for $150 \mathrm{~min}$ to achieve the temperature stabilization and homogenization of the metal melt. Consequently, the alumina spindle was immersed into the melt, and flow curves were recorded at a temperature of $1,550^{\circ} \mathrm{C}$. The viscosity was measured during cooling in the temperature range from the temperature of $1,550^{\circ} \mathrm{C}$ to $1,450{ }^{\circ} \mathrm{C}\left(1,350{ }^{\circ} \mathrm{C}\right)$ at a cooling rate of $2.5^{\circ} \mathrm{C} / \mathrm{min}$. From the course of viscosity dependence on shear rate, an optimum a shear rate 
of 10 1/s was chosen for the viscosity measurement. Further, the flow behaviour of tested samples was also investigated in the semi-solid state at the temperature of $1,450^{\circ} \mathrm{C}$ through flow curves.

\section{RESULTS AND DISCUSSION}

\subsection{Flow curves}

The flow properties of fluids (melts) are mathematically ascribed by rheological equations of the state which usually express the relationship between the deformation shear (tangent, viscous) stress $\tau$ and deformation of fluid. Flow curves are their graphical representations. From the shape of the flow curve, it is possible to assess the Newtonian or non-Newtonian behaviour of fluids. Newtonian fluids are those that obey Newton's law of viscosity, according to which, under simple shear flow, the shear viscosity is independent of shear rate. For non-Newtonian fluids, their viscosity either decreases with shear rate (shear-thinning behaviour) or increases with shear rate (shear-thickening behaviour). Figures 1 and $\mathbf{2}$ show flow curves expressed as a dependence of shear stress on shear rate for all examined samples at $1,550^{\circ} \mathrm{C}$. The power law model (Equation (1)) was fitted to experimentally obtained data. The parameters values of the given equation are listed in Table 2. In all cases, parameter $n$ was larger than 1 pointing to shear-thickening behaviour of melt samples.

$\tau=K \cdot \dot{\gamma}^{n}$

where $\tau(\mathrm{Pa})$ - the shear stress, $K\left(\mathrm{~Pa} \cdot \mathrm{s}^{n}\right)$ - the flow consistency index, $\dot{\gamma}(1 / \mathrm{s})$ - the shear rate, $n(-)$ - the flow behaviour index.

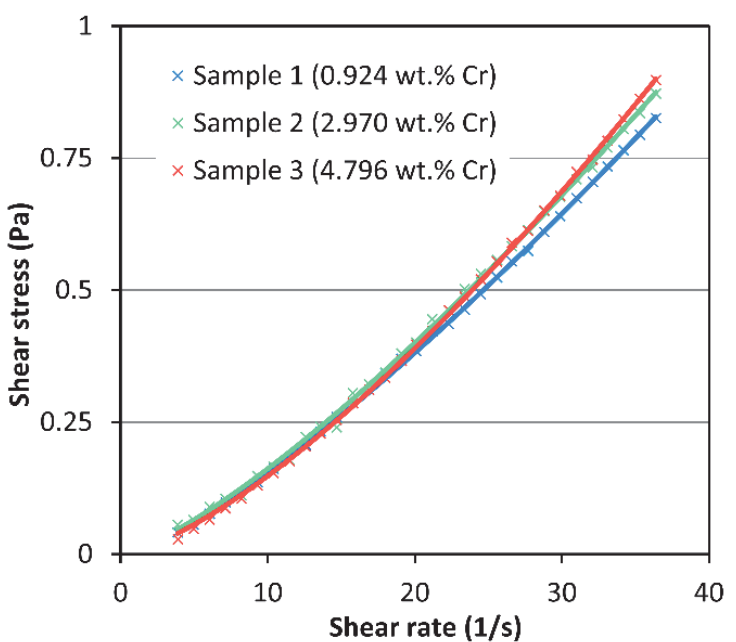

Figure 1 Flow curves for samples $1-3$ at $1,550^{\circ} \mathrm{C}$, solid lines denote fitted curves

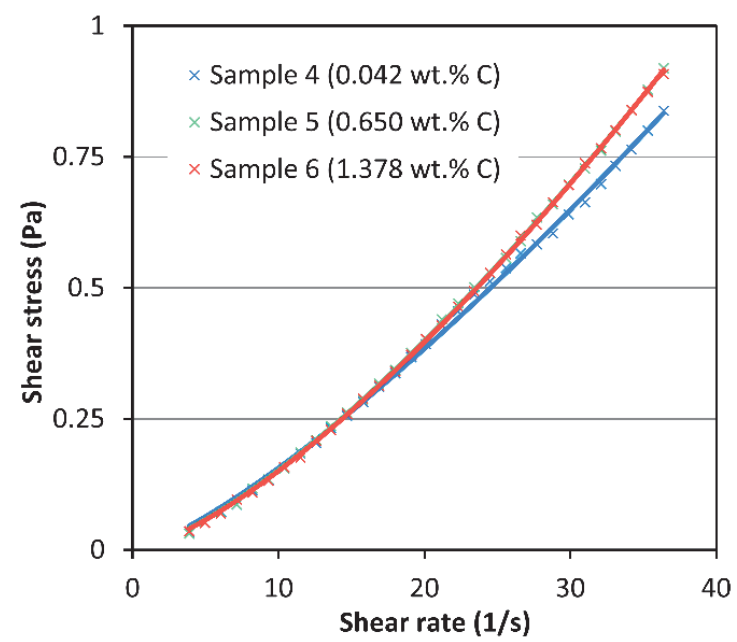

Figure 2 Flow curves for samples 4 - 6 at 1,550 ${ }^{\circ} \mathrm{C}$, solid lines denote fitted curves

Furthermore, in Figures 3 and $\mathbf{4}$, the dependencies of dynamic viscosity on shear rate are presented for all samples at $1,550{ }^{\circ} \mathrm{C}$. The Carreau-Yasuda model (Equation (2)) was used for fitting experimental data. Optimized and rounded off parameters of the model are included in Table 3.

Table 2 Optimized parameters of the power law model

\begin{tabular}{|c|c|c|c|c|c|}
\hline Sample & $\boldsymbol{K}\left(\mathbf{P a} \cdot \mathbf{s}^{\mathbf{n}}\right)$ & $\boldsymbol{n}(-)$ & Sample & $\boldsymbol{K}\left(\mathbf{P a} \cdot \mathbf{s}^{\mathbf{n}}\right)$ & $\boldsymbol{n}(-)$ \\
\hline $\mathbf{1}$ & $7.84 \cdot 10^{-3}$ & 1.30 & $\mathbf{4}$ & $7.93 \cdot 10^{-3}$ & 1.30 \\
\hline $\mathbf{2}$ & $7.99 \cdot 10^{-3}$ & 1.31 & $\mathbf{5}$ & $6.22 \cdot 10^{-3}$ & 1.39 \\
\hline $\mathbf{3}$ & $5.92 \cdot 10^{-3}$ & 1.40 & $\mathbf{6}$ & $6.02 \cdot 10^{-3}$ & 1.40 \\
\hline
\end{tabular}


$\eta=\eta_{\infty}+\left(\eta_{0}-\eta_{\infty}\right) \cdot\left[1+(\lambda \cdot \dot{\gamma})^{\alpha}\right]^{\frac{n-1}{\alpha}}$

where $\eta_{0}(\mathrm{~Pa} \cdot \mathrm{s})$ - viscosity at zero shear rate, $\eta_{\infty}(\mathrm{Pa} \cdot \mathrm{s})$ - viscosity at infinity shear rate, $\lambda(\mathrm{s})$ - phase shift, $n(-)$ - power law coefficient, $\alpha(-)$ - Yasuda coefficient, $\dot{\gamma}(1 / \mathrm{s})$ - the shear rate.

Table 3 Parameters values of Yasuda-Carreau model for steel samples $1-6$ at temperature $1,550{ }^{\circ} \mathrm{C}\left({ }^{*}\right)$ and $1,450{ }^{\circ} \mathrm{C}\left({ }^{* *}\right)$

\begin{tabular}{|c|c|c|c|c|c|c|c|c|c|c|}
\hline \multirow{2}{*}{ Sample } & \multicolumn{2}{|c|}{$\eta_{0}(\mathbf{P a} \cdot \mathbf{s})$} & \multicolumn{2}{|c|}{$\eta_{\infty}(\mathbf{P a} \cdot \mathbf{s})$} & \multicolumn{2}{c|}{$\lambda(\mathbf{s})$} & \multicolumn{2}{|c|}{$\boldsymbol{n}(-)$} & \multicolumn{2}{|c|}{$\alpha(-)$} \\
\cline { 2 - 12 } & $\times 10^{4(*)}$ & $\times 10^{-1(* *)}$ & $\times 10^{2(*)}$ & $\times 10^{1(*)}$ & $\times 10^{2(*)}$ & $\times 10^{1 * *}$ & $\times 10^{1(*)}$ & $\times 10^{1(*)}$ & $\times 10^{1(*)}$ & $\left(^{(* *)}\right.$ \\
\hline $\mathbf{1}$ & 1.31 & 4.76 & 4.84 & 8.71 & 20.22 & 12.35 & 7.28 & -11.89 & 7.04 & 29.83 \\
\hline $\mathbf{2}$ & 105.77 & 11.58 & 3.68 & 8.54 & 12.40 & 28.71 & 5.46 & -7.21 & 17.11 & 11.56 \\
\hline $\mathbf{3}$ & 13.00 & 13.67 & 12.25 & 3.11 & 39.72 & 22.86 & 9.21 & -7.52 & 15.84 & 11.56 \\
\hline $\mathbf{4}$ & 45.89 & - & 2.82 & - & 14.15 & - & 1.59 & - & 14.22 & - \\
\hline $\mathbf{5}$ & 3.66 & 14.26 & 12.87 & 7.44 & 27.11 & 14.02 & 9.12 & -11.52 & 9.18 & 31.88 \\
\hline $\mathbf{6}$ & 3.75 & 2.93 & 16.29 & 4.95 & 9.97 & 5.26 & 9.08 & -7.23 & 6.84 & 2.44 \\
\hline
\end{tabular}

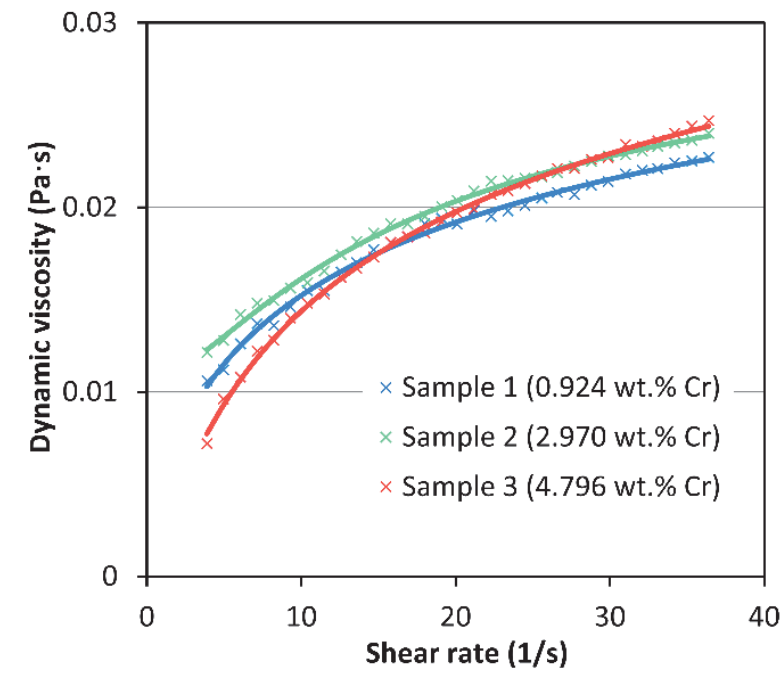

Figure 3 Dynamic viscosity versus shear rate for samples $1-3$, temperature $1,550^{\circ} \mathrm{C}$, solid lines denote fitted curves

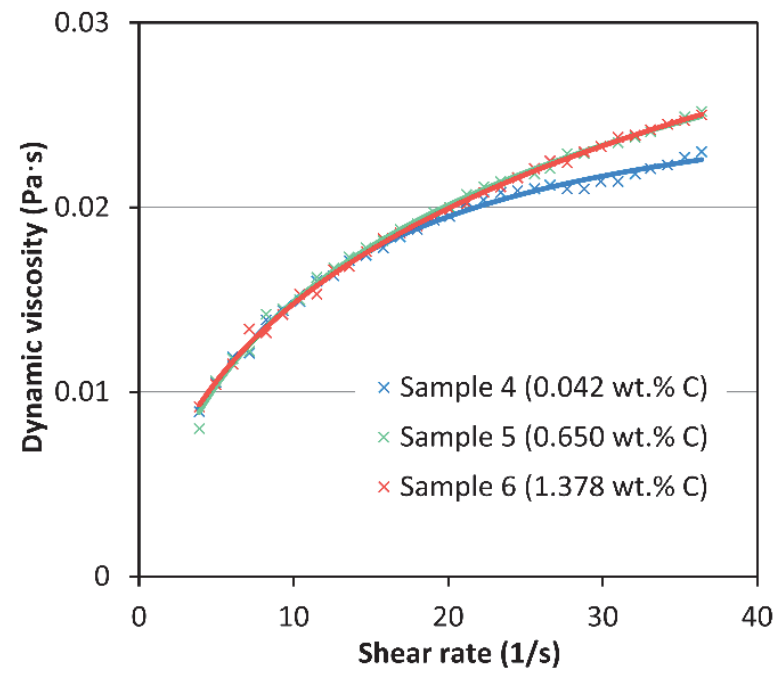

Figure 4 Dynamic viscosity versus shear rate for samples 4 - 6 , temperature $1,550^{\circ} \mathrm{C}$, solid lines denote fitted curves

From the course of individual dependencies of dynamic viscosity on shear rate, it can be concluded that the investigated melts exhibit shear-thickening behaviour at $1,550^{\circ} \mathrm{C}$ (in a liquid state). Besides, flow curves were recorded at $1,450{ }^{\circ} \mathrm{C}$ (in a semi-solid state), see Figures $\mathbf{5}$ and $\mathbf{6}$. Experimentally obtained data were also fitted to the Carreau-Yasuda model.

Individual parameters can be found in Table 3. For sample 4, the dependence was not plotted because the maximum torque was reached at a temperature higher than $1,450{ }^{\circ} \mathrm{C}$. Contrary to $1,550{ }^{\circ} \mathrm{C}$, the dynamic viscosity of all samples decreased with increasing shear rate $(n<1)$. Therefore, at $1,450{ }^{\circ} \mathrm{C}$, alloy samples showed shear-thinning behaviour. 


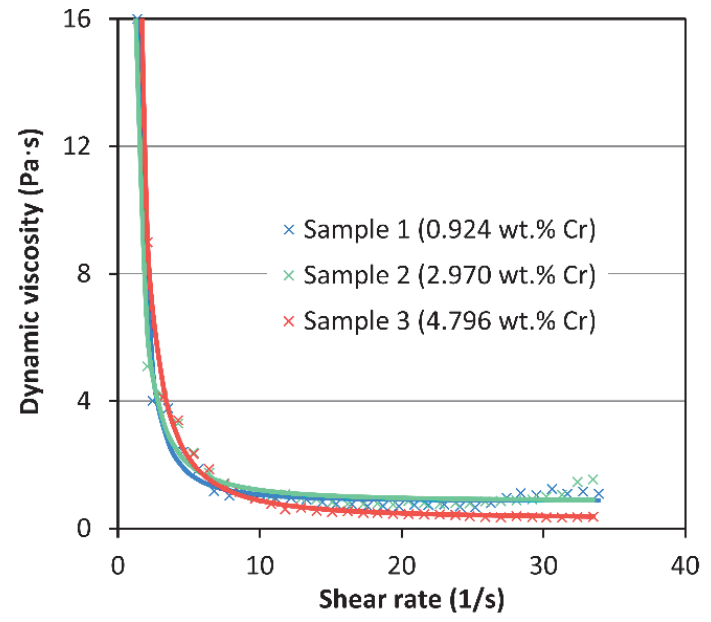

Figure 5 Dynamic viscosity versus shear rate for samples $1-3$, temperature $1,450^{\circ} \mathrm{C}$, solid lines denote fitted curves

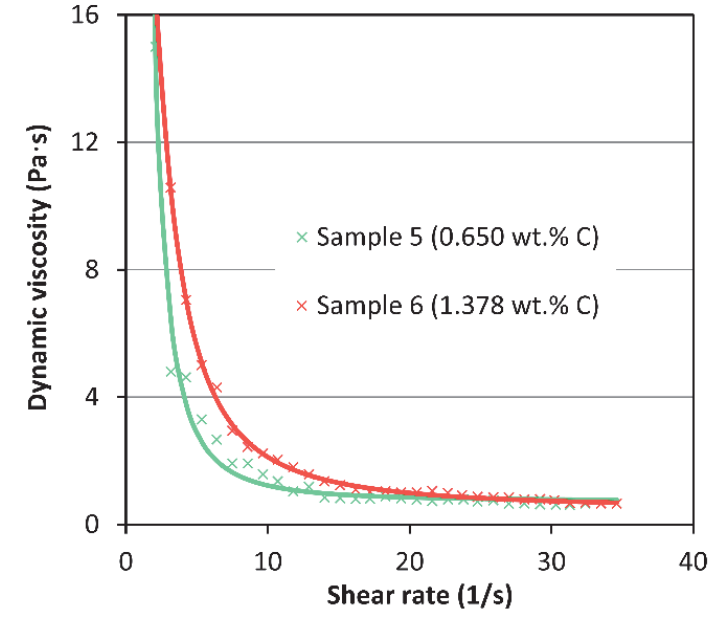

Figure 6 Dynamic viscosity versus shear rate for samples $5-6$, temperature $1,450{ }^{\circ} \mathrm{C}$, solid lines denote fitted curves

\subsection{Dependence of dynamic viscosity on temperature}

Figures 7 and 8 show the temperature dependencies of dynamic viscosity for all investigated alloy samples. As illustrated in the figures below, an exponential increase in viscosity with decreasing temperature is evident. From a detailed view concerning liquidus state, a very slight viscosity dependence on chromium (see Figure 7) and carbon content (see Figure 8) can be seen. In the studied concentration ranges of chromium (0.924 wt. \% - 4.760 wt. $\%$ ) and carbon ( $0.042 \mathrm{wt} . \%-1.378 \mathrm{wt} . \%)$, there is a slight increase in viscosity with increasing content of both elements.

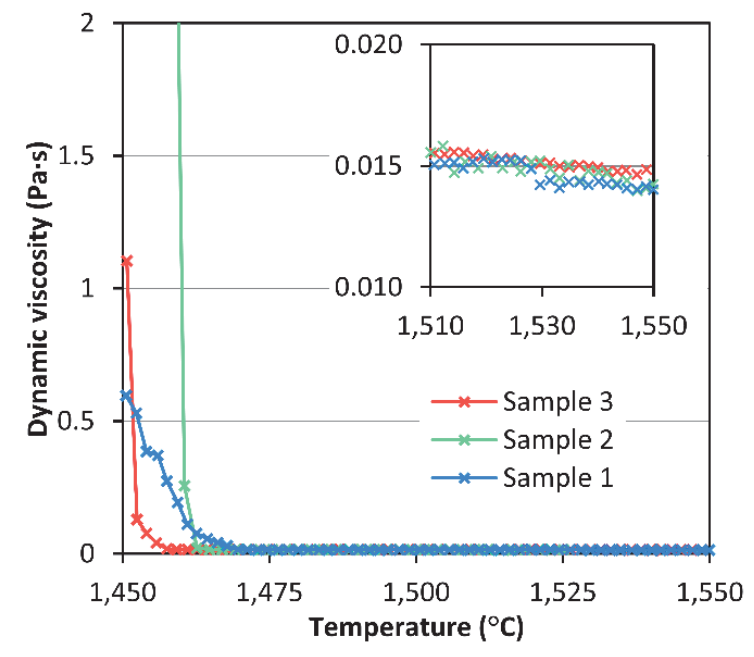

Figure 7 Dependencies of dynamic viscosity on temperature for samples 1 - 3

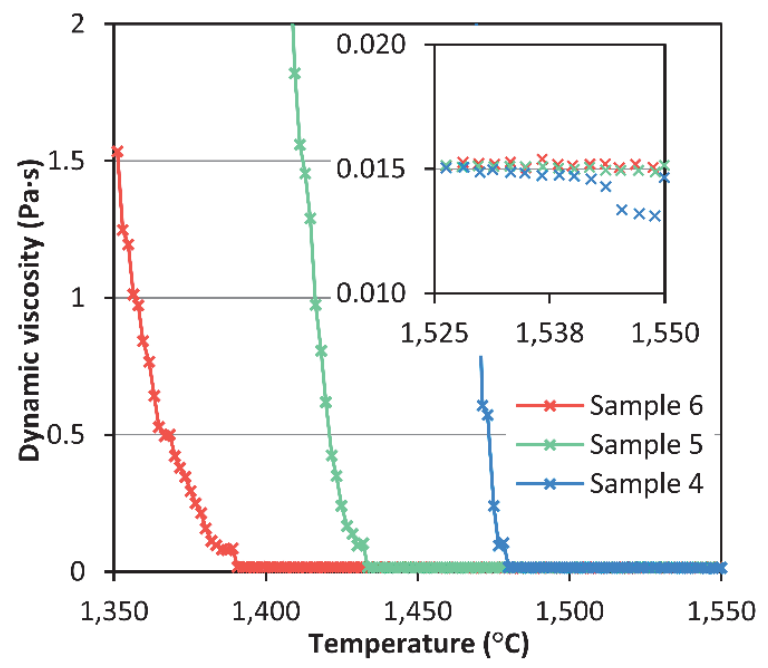

Figure 8 Dependencies of dynamic viscosity on temperature for samples 4 - 6

\section{CONCLUSION}

The results obtained by the experimental research can be summarized as follows:

- $\quad$ According to the course of flow curves, non-Newtonian behaviour of the investigated alloy samples was approved. At $1,550^{\circ} \mathrm{C}$, in a liquid state, the samples showed the shear-thickening behaviour, while at $1,450{ }^{\circ} \mathrm{C}$ in a semi-solid state, they exhibited shear-thinning behaviour. 
- $\quad$ Experimental data concerning flow curves in the form of dependence of shear stress on shear rate were successfully fitted using the power law model. Experimentally obtained data of dynamic viscosity versus shear rate dependence were also effectively fitted by Carreau-Yasuda model. Based on the calculated parameters of both models, the above-mentioned behaviour was confirmed.

- Dynamic viscosity of all investigated alloys was rising with decreasing temperature.

- $\quad$ From assessment of the influence of chromium and carbon content on dynamic viscosity value of alloy samples in a liquid state, it can be stated that its dependence in concentration ranges of chromium (0.924 wt. \% - $4.760 \mathrm{wt} . \%)$ and carbon (0.042 wt.\% - $1.378 \mathrm{wt} . \%)$ was negligible. The dynamic viscosity of the alloy samples increased very slightly with increasing contents of both elements.

\section{ACKNOWLEDGEMENTS}

This paper was created within the frame of the project GACR reg. number 17-18668S and students projects SP2019/90, SP2019/74, SP2019/43 (Faculty of Materials Science and Technology) and "Support of gifted students of doctoral studies at VŠB-TUO" no.: 04766/2017 / RRC (MoravianSilesian Region).

\section{REFERENCES}

[1] BAKHTIYAROV, Sayavur I. and OVERFELT, Ruel A. Measurement of liquid metal viscosity by rotational technique. Acta Materialia. 1999. vol. 47, no. 17, pp. 4311-4319.

[2] FRENKEL, Jacob. Kinetic Theory of Liquids. 1st ed. Oxford: Clarendon Press, 1946. p. 485.

[3] IIDA, Takamichi and GUTHRIE, Roderick I. L. The Physical Properties of Liquid Metals. Oxford: Clarendon Press, 1988. p. 312.

[4] CHHABRA, Rajendra P. and RICHARDSON, John F. Non-Newtonian Flow in the Process Industries: Fundamentals and Engineering Applications. 1st ed. Oxford: Butterworth-Heinemann, 1999. p. 436.

[5] TOCCI, Marialaura, ZANG, Christoph, ZUECO, Ines C., POLA, Annalisa and MODIGELL, Michael. Rheological properties of liquid metals and semisolid materials at low solid fraction. Solid State Phenomena. 2016. vol. 256, pp. 133-138.

[6] VARSANI, Vijay and FAN, Zhongyun. Non-Newtonian behaviour of liquid metals. Transactions of the Indian Institute of Metals. 2007. vol. 60, no. 2-3, pp. 251-256.

[7] SOŁEK, Krzysztof. Identification of the steel viscosity and dynamic yield stress for the numerical modelling of casting simulations in the semi-solid state. Archives of Metallurgy and Materials. 2017. vol. 62, no. 1, pp. 195-200. 